\title{
Characterization of Plasmodium falciparum glutamate dehydrogenase-soluble antigen
}

\section{A. Rodríguez-Acostal, N.G. Domínguez I. Aguilar ${ }^{1}$ and M.E. Girón ${ }^{1}$}

\author{
${ }^{1}$ Seccion de Inmunoquimica, Instituto de Medicina Tropical, and \\ ${ }^{2}$ Laboratorio de Bioquimica, Facultad de Farmacia, \\ Universidad Central de Venezuela, Caracas, Venezuela
}

Correspondence

A. Rodríguez-Acosta

Apartado 47423

Caracas 1041-A

Venezuela

Fax: 5826932094

E-mail: rodriguf@ camelot.rect.ucv.ve

Research supported by the Consejo de Desarrollo Científico y Humanístico (No. 09.34.0173.93) and Instituto de Investigaciones

Farmaceuticas de la Universidad Central de Venezuela.

Received May 7, 1997 Accepted May 27, 1998

\section{Abstract}

The major aim of this study was to characterize a soluble Plasmodium falciparum antigen from the plasma of malaria-infected humans and Plasmodium falciparum culture supernatants, using immunoabsorbent techniques and Western blotting. An Mr 60-kDa protein was isolated from the plasma of patients with Plasmodium falciparum malaria by affinity chromatography using rabbit anti-Proteus spp GDH(NADP $\left.{ }^{+}\right)$ serum as ligand. This protein, present in plasma of patients with acute Plasmodium falciparum infection, in Plasmodium falciparum culture supernatants, and in immune complexes, was tested with Plasmodium falciparum malaria hyperimmune serum from patients living in hyperendemic areas and rabbit anti-Proteus spp GDH(NADP ${ }^{+}$) serum prepared in the laboratory. In this report, we describe the results of a study showing that parasite $\mathrm{GDH}\left(\mathrm{NADP}^{+}\right)$can be used to detect the presence of Plasmodium falciparum. It appears that this technique permits the chromatographic detection of a Plasmodium falciparum excretion antigen that may be used in the production of monoclonal antibodies to improve immunodiagnostic assays for the detection of antigenemia, and opens the possibility of its use as a non-microscopic screening method.

\section{Introduction}

Malaria is still one of the most important and devastating tropical diseases, and Plasmodium falciparum kills about 2-3 million people per year (1). A concerted effort is necessary to improve the diagnostic methods to control the disease.

Among the compounds inherent to the parasite there are certain enzymes that could be effective as markers in malaria diagnosis (2). The difficulty encountered in isolating them from the plasma of patients or in cultures of Plasmodium falciparum is the fact that only minimal quantities are obtained

\section{Key words}

- Glutamate-dehydrogenase

- Plasmodium falciparum

- Exoantigens

- Soluble antigens

- Malaria

- Antigenic enzymes and it is difficult to separate the parasitic material from the host products. In general, it may be stated that the parasite has a metabolism similar to the host, but the characteristics of many enzymes compromised in these pathways have been considered to be different. Among these enzymes, this study will concentrate on glutamate dehydrogenase whose presence was suspected on the basis of appearance of an Mr 60-kDa band whose enzymatic activity was confirmed by means of an enzymatic assay (RodríguezAcosta A, Gamboa de DN, Aguilar I and Girón ME, unpublished data). In that study we detected the enzymatic activity of Plas- 
modium falciparum $\mathrm{GDH}\left(\mathrm{NADP}^{+}\right)$in the plasma of acute malaria patients, captured by a rabbit polyclonal anti-Proteus spp $\mathrm{GDH}\left(\mathrm{NADP}^{+}\right)$, which took advantage of the immunologic relationships existing between the enzymes of the two species (3).

This GDH(NADP ${ }^{+}$) activity of Plasmodium falciparum differs from mammalian GDH in several features: kinetics, substrate, specificity of co-factors, degree of affinity and immunogenicity (4-7). This report suggests that Plasmodium falciparum glutamate dehydrogenase-soluble antigen may be used as a target antigen in systems designed to detect malarial disease.

\section{Material and Methods}

\section{Animals}

New Zealand rabbits weighing $2 \mathrm{~kg}$ were used to obtain sera against whole parasite, culture supernatant and GDH(NADP ${ }^{+}$.

\section{Sample collection}

Blood samples were collected from patients attending the Malaria Consultation Center at the Ciudad Bolivar Malariology Division. Ciudad Bolivar is a city located in the northern part of Bolivar State, Venezuela. Many of the patients are migrant gold miners who routinely spend 20 to 30 days prospecting in the tropical forest where most of their infections originate. A total of 30 patients with acute malaria were recruited for the study as a source of antigens. All the patients gave oral informed consent to participate in the study. Each patient was interviewed and address, place of origin and information about whether or not the patient had been treated with anti-malarial drugs were recorded in a questionnaire.

Blood samples from the patients (approximately $20 \mathrm{ml}$ ) were collected into test tubes that contained an anticoagulant and $100 \mu \mathrm{l}$ of a mixture of proteinase inhibitors $(0.15$
mM TPCK (Sigma Chemical Co., St. Louis, MO), $200 \mathrm{mM}$ PMFS (Sigma), $0.2 \mathrm{mM}$ EDTA in PBS). The plasma was separated to be used as a source of antigens and stored at $-70^{\circ} \mathrm{C}$ until use.

\section{Parasite culture}

Plasmodium falciparum parasites (Venezuelan isolates) were cultured with human erythrocytes at 2\% hematocrit in RPMI-1640 media and $10 \%$ human serum (8). The media were changed every $24 \mathrm{~h}$, treated with a protease inhibitor cocktail and stored at $-70^{\circ} \mathrm{C}$ until use.

Fractionated precipitation of the Plasmodium falciparum culture supernatant

Approximately $300 \mathrm{ml}$ of culture supernatant was concentrated (30 times) inside a dialysis bag by dehydration with Aquacide II. The concentrate was subjected to fractionated precipitation with ammonium sulfate using 33, 40 and $50 \%$ saturation. The precipitates obtained in each step were collected in PBS and analyzed by Western blotting.

\section{Precipitation of immune complexes}

In another group of experiments we analyzed the immune complexes formed in situ by a combination of a) plasma from patients with acute Plasmodium falciparum infections and Yanumana Amerindian sera (hyperimmune) at a proportion of 5:1 and b) plasma from patients with acute Plasmodium falciparum infections with antiGDH(NADP ${ }^{+}$) antibodies of Proteus spp produced in rabbits at a proportion of 20:1.

The precipitation of immunocomplexes was effected in accordance with the protocol utilized by the Laboratório de Malária (Malaria Laboratory), Instituto Oswaldo Cruz, Rio de Janeiro, Brazil (C. Ribeiro, personal communication). The mixtures were treated with polyethylene glycol 8,000 (PEG 8,000) 
(Sigma) at 2.5\% final concentration and left on ice for $2.5 \mathrm{~h}$. The samples were centrifuged at 2,500 $\mathrm{g}$ for $20 \mathrm{~min}$ at $4^{\circ} \mathrm{C}$ and the precipitate was washed with a solution of 2.5\% PEG 8,000 in PBS, pH 7.2, and subsequently dialyzed against $1 \mathrm{mM}$ PBS, pH 7.2, for $2 \mathrm{~h}$ at $4^{\circ} \mathrm{C}$, and absorbance at $280 \mathrm{~nm}$ was determined. The material obtained was analyzed by the Western blot method. Normal serum was used as a control and subjected to the same procedure.

\section{Antibody preparation}

Antibodies were obtained from plasma of adult Yanumana Indians of both sexes living in hyperendemic areas of malaria (Amazonas State, Venezuela), diagnosed as being infected with Plasmodium falciparum and having experienced two or more malaria episodes. Anti-malaria IgG was isolated from the plasma of hyperimmune adult patients by salting out and ion exchange chromatography (DEAE cellulose; Sigma) as described (9).

\section{GDH(NAD $\left.P^{+}\right)$immunoaffinity separation}

Blood plasma ( $400 \mathrm{mg}$ protein) as a source of antigens from patients with acute Plasmodium falciparum infections was loaded on columns of Sepharose-4B-rabbit-IgG antiGDH(NADP ${ }^{+}$) of Proteus spp. The columns were washed with PBS until absorbance at $280 \mathrm{~nm}$ was equal to 0 . The protein absorbed to the column was eluted with $0.1 \mathrm{M}$ glycine$\mathrm{HCl}$ buffer, $\mathrm{pH} 2.6$, concentrated (Figure 1), and analyzed by Western blot. Plasma from normal patients was treated in the same manner as the plasma from malaria patients.

\section{Anti-whole-parasite serum}

The infected erythrocytes $(20 \mathrm{ml})$ derived from cultures with a parasitemia of at least $3 \%$ were suspended in $\mathrm{PBS}, \mathrm{pH} 7.2$, and centrifuged at $300 \mathrm{~g}$ for $10 \mathrm{~min}$ at $4^{\circ} \mathrm{C}$. After being washed with PBS three times, the eryth-

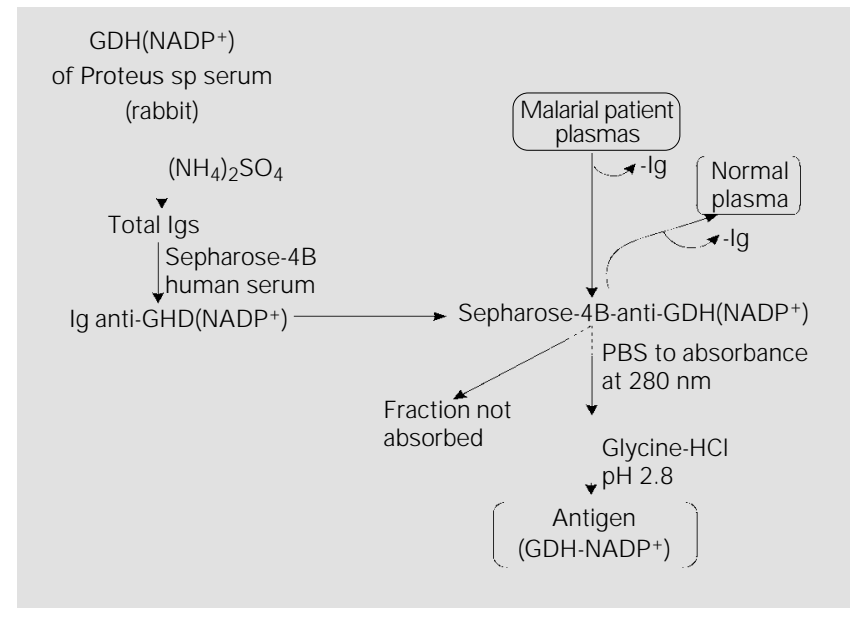

Figure 1 - Procedure for the separation of $\mathrm{GDH}(\mathrm{NADP}+)$ from malarial patient plasmas by affinity chromatography.

rocytes were lysed with saponin (Sigma) at a final concentration of $0.1 \%$ for $15 \mathrm{~min}$ at room temperature, washed and resuspended again in $0.5 \mathrm{ml}$ of PBS which contained $0.1 \%$ of the mixture of protease inhibitors (crude preparation of parasite extracts).

This antigen was utilized to immunize the rabbits and obtain anti-whole-parasite serum as described (9). This serum was used in the immunoblotting analysis of the antigens to be studied.

\section{Preparation of IgG anti-culture supernatant}

Approximately $300 \mathrm{ml}$ of culture supernatant was concentrated (30 times) inside a dialysis bag by dehydration with Aquacide II (Calbiochem, San Diego, CA). The concentrate was precipitated with $33 \%$ ammonium sulfate to eliminate the human serum immunoglobulins present in the culture medium. The protein concentration of the immunoglobulin-free supernatant was determined and the supernatant was then used to prepare anti-culture supernatant serum by inoculating rabbits as described (9). The serum of immunized rabbits was used to prepare $\mathrm{IgG}$ by precipitation with $33 \%$ ammonium sulfate and DEAE cellulose (Sigma) ion exchange chromatography. This IgG (100 mg 
protein $/ \mathrm{ml}$ ) was absorbed by incubation with a mixture of red blood cells (MRBC) type $0^{+}$, $\mathrm{A}^{+}$and $\mathrm{B}^{+}(1: 1: 1)$, maintaining the relationship of $1 \mathrm{ml} \mathrm{MRBC}$ to $3 \mathrm{ml} \mathrm{IgG}$, for $2 \mathrm{~h}$ at $4^{\circ} \mathrm{C}$, and centrifuged at $200 \mathrm{~g}$ for $10 \mathrm{~min}$, and the supernatant was separated out. This supernatant was passed through a column of Sepharose-4B-human serum and the recovered eluate was concentrated by Aquacide II dehydration. This preparation of purified Ig was used to perform the immunoblotting analysis of the antigens to be studied.

\section{Preparation of rabbit peroxidase-conjugated anti-Proteus spp GDH(NADP+) IgG}

The serum of rabbits immunized against Proteus spp GDH(NADP ${ }^{+}$) (Sigma) was used to prepare $\operatorname{IgG}$ by saline precipitation with $33 \%$ ammonium sulfate and ion exchange

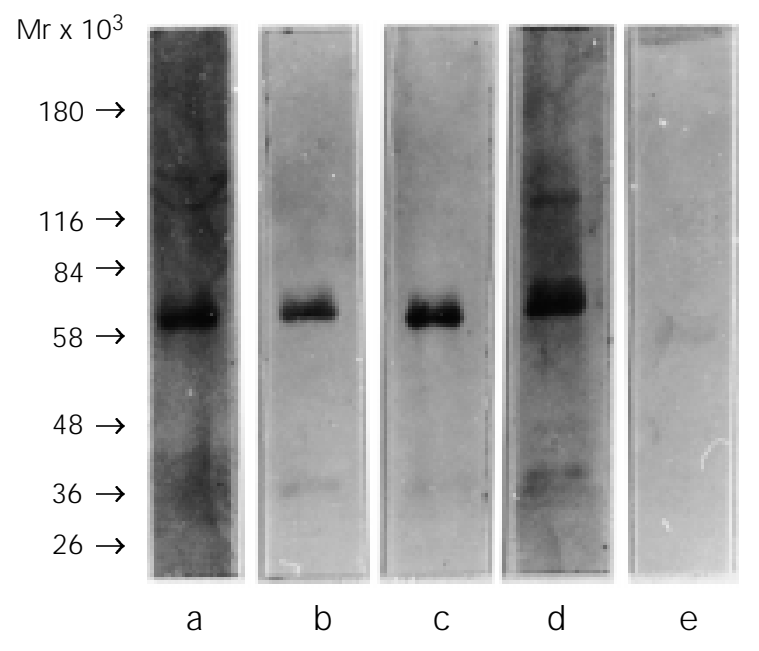

Figure 2 - Western blot analysis of the antigenic fraction present in malarial plasmas of patients infected with Plasmodium falciparum separated through columns of Sepharose-4B linked to anti-Proteus spp GDH(NADP $\left.{ }^{+}\right)$IgG. The electrophoretic separation was carried out in 7.5\% SDS-polyacrylamide gels under reducing conditions. Immunologic detection was obtained by incubation with:

a, Anti-Proteus spp GDH(NADP $\left.{ }^{+}\right)$serum/anti-lgG rabbit-peroxidase.

b, Anti-culture supernatant of Plasmodium falciparum/antiIgG rabbit-peroxidase.

c, Anti-whole-parasite (Plasmodium falciparum)/anti-lgG rabbit-peroxidase.

d, Hyperimmune (Yanumana) serum/anti-lgG-human-peroxidase.

e, Normal patient serum/anti-lgG-human-peroxidase.
DEAE-cellulose chromatography (Sigma). The IgG fraction enriched with anti$\mathrm{GDH}\left(\mathrm{NADP}^{+}\right)$antibodies was used to prepare Sepharose-4B anti-GDH(NADP $\left.{ }^{+}\right)$IgG, and the peroxidase conjugate (9). This conjugate was used in the immunoblotting analysis of the different antigen preparations studied.

\section{Polyacrylamide gel electrophoresis}

Electrophoresis was carried out by the method of Laemmli (10) using a Dual Mini Slam Kit AE-6450 (Atto Corporation, Tokyo, Japan) chamber. The development gels were prepared at $7.5 \%$ or in gradients of 5 $15 \%$ and in all cases the concentration gel was prepared at $4.5 \%$.

\section{Western blotting}

The original immunoblotting technique (11) was used. The electrophoresed proteins were blotted onto nitrocellulose using a semidry electrotransfer chamber with graphite electrodes (Atto Corporation). The material transferred was analyzed by immunostaining using specific antibodies.

\section{Results}

Complete data was obtained for all patient sera tested. Of these $100 \%$ were parasitologically positive for Plasmodium falciparum and negative for other Plasmodium species. The parasite carriers with acute Plasmodium falciparum infections showed a parasite density of $10,000 / \mu l$.

To characterize the antigens present in plasma, captured by a column of Sepharose4B-anti-Proteus spp GDH(NADP ${ }^{+}$, we separated the antigens in polyacrylamide gels and electrotransferred them for the Western blot analysis. The result (Figure 2a) shows that the parasite excretes a protein which is recognized by anti-Proteus spp GDH $\left(\mathrm{NADP}^{+}\right)$serum/anti-rabbit IgG peroxidase, that corresponded to a protein with $\mathrm{Mr}$ of 
approximately $60 \mathrm{kDa}$.

The polyclonal anti-culture supernatants and anti-whole-parasite, as well as the hyperimmune serum of the Yanumana Indians, were also able to recognize the $60-\mathrm{kDa}$ band (Figure 2b,c,d).

In the Western blot analysis of crude preparations of parasites, the complex composition of the sample becomes evident by the use of an antiserum produced against the proteins of the whole parasite. A band with the same electrophoretic migration (approximately $60 \mathrm{kDa}$ ) is also recognized by the hyperimmune serum of Yanumana Indians and by the anti-Proteus spp GDH(NADP ${ }^{+}$peroxidase conjugate (Figure 3 ).

The Western blot analysis of the $40 \%$ ammonium sulfate-precipitated fraction of the culture supernatant of Plasmodium falciparum is shown in Figure 4. When developed with the polyclonal anti-Proteus spp GDH(NADP $\left.{ }^{+}\right)$-peroxidase, a band with a molecular mass of approximately $60 \mathrm{kDa}$ appears, similar to that obtained from the plasma of acute Plasmodium falciparum infections.

The Western blot analysis of immuneperoxidase-conjugated anti-Proteus spp $\mathrm{GDH}\left(\mathrm{NADP}^{+}\right) \mathrm{IgG}$ indicated the presence of a $60-\mathrm{kDa}$ protein (Figure 5).

\section{Discussion}

The identification and description of new malarial antigens should contribute to improving both the individual and mass diagnosis of this endemic disease, as well as the incorporation of antigens relevant to the preparation of new vaccines. To date, studies focused in this direction have not been consolidated. In this regard, the main purpose of the present study was to identify the products of excretion that could be associated with infection by Plasmodium falciparum. The discovery of a $60-\mathrm{kDa}$ protein in the plasma of acute Plasmodium falciparum infections, in the culture supernatant of Plas-

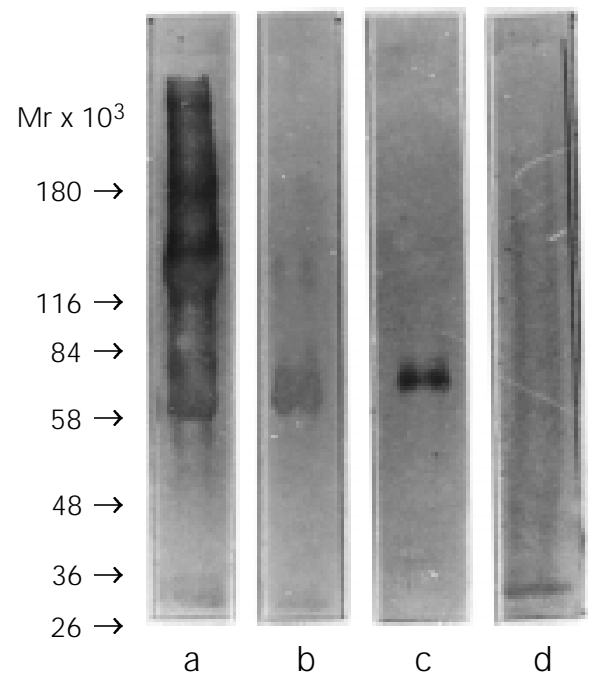

Figure 3 - Western blot analysis of a crude preparation of Plasmodium falciparum. The electrophoretic separation was carried out in $7.5 \%$ SDS-polyacrylamide gels under reducing conditions. Immunologic detection of the material transferred was obtained by incubation of the nitrocellulose strips with:

a, Anti-whole-parasite (Plasmodium falciparum) serum/anti-lgG rabbit-peroxidase.

b, Hyperimmune (Yanumana) serum/anti-IgG human-peroxidase.

c, Anti-GDH(NADP $\left.{ }^{+}\right)$-peroxidase.

d, Normal patient serum/anti-lgG human-peroxidase.

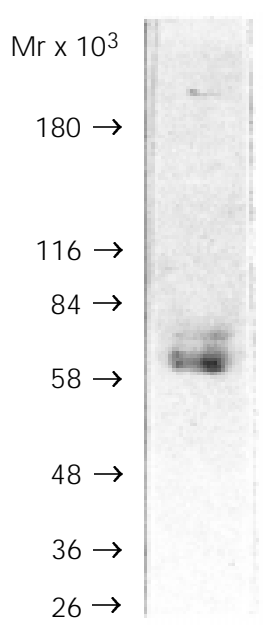

Figure 4 - Western blot analysis of Plasmodium falciparum culture supematant fraction precipitated at $40 \% \mathrm{SO}_{4}\left(\mathrm{NH}_{4}\right)_{2}$. The electrophoretic separation was carried out in $10 \%$ SDS-polyacrylamide gels under reducing conditions. Immunologic detection was obtained by incubation of the nitrocellulose strips with anti-GDH $\left(\mathrm{NADP}^{+}\right)$-peroxidase.

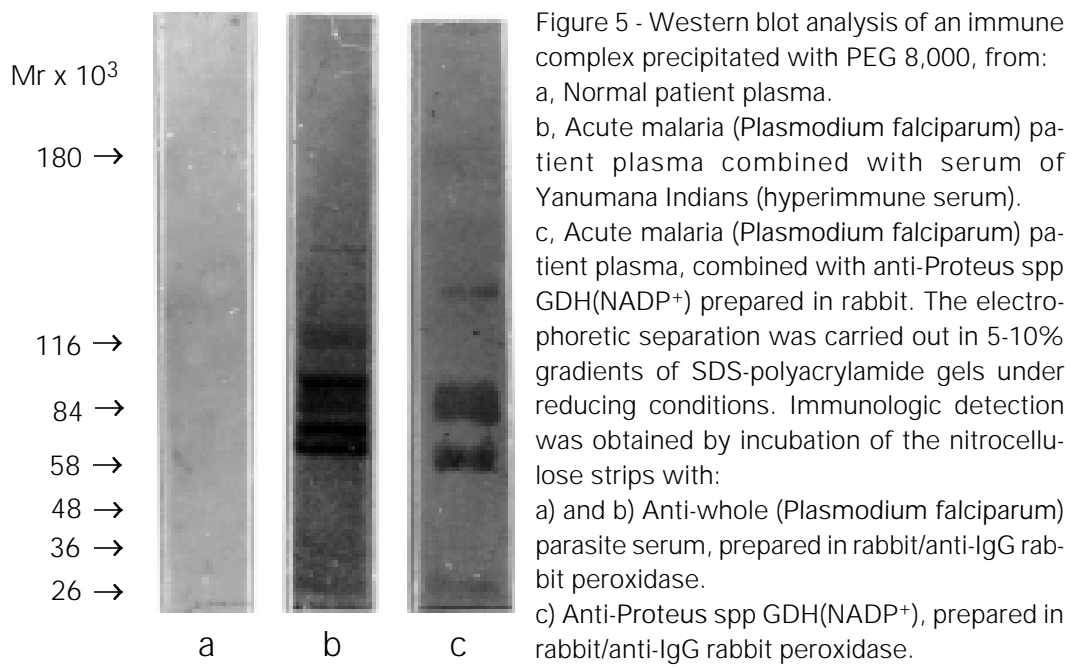


modium falciparum and in the isolated immune complexes allows us to make an inference regarding its high level of immunogenicity and distribution. The inclusion of antiwhole-parasite polyclonal antibodies in our Western blotting experiments has proved to be a valuable tool in the characterization of this antigen. As commented in the Introduction (Rodríguez-Acosta A, Gamboa de DN, Aguilar I and Girón ME, unpublished data) we have detected the GDH(NADP $\left.{ }^{+}\right)$enzymatic activity of this $60-\mathrm{kDa}$ protein and evidence is provided that GDH reactivity correlates with parasite burden.

Following a strategy similar to that used by Riha et al. (12) we decided to analyze from an immunological viewpoint the immune complexes generated when the plasma of acute Plasmodium falciparum infections reacted with polyclonal anti-GDH(NADP $\left.{ }^{+}\right)$ and also with the hyperimmune serum from Yanumana Indians. The immunological development of the immune complexes precipitated by PEG 8,000 from prior mixtures (Figure 5) using the polyclonal anti-wholeparasite prepared in rabbits allowed us to observe the presence of a series of bands (absent in normal plasma), including one which has a molecular weight of approximately $60 \mathrm{kDa}$. Considering the heterological nature of the antiserum used in immunodevelopment (anti-whole-parasite prepared in the rabbit), the parasitological nature of this antigen is once again confirmed.

Another important discovery in the present study was the fact that the antigen under study was recognized by the naturally acquired antibodies of the Yanumana Indians (Figures 3 and 4). The serum of these patients, although it may prove to be heterogeneous, had the advantage of being an indicator of those antigens that produce a good immunological response.

Van Der Jagt et al. (13), who purified the $\mathrm{GDH}\left(\mathrm{NADP}^{+}\right)$of Plasmodium falciparum using HPLC, report a band of close to 230 $\mathrm{kDa}$. Our results, obtained under reducing conditions, led to the interpretation that native $\mathrm{GDH}\left(\mathrm{NADP}^{+}\right)$could correspond to a protein consisting of 4 subunits. GDH $\left(\mathrm{NADP}^{+}\right)$shows no cross-reaction with the enzyme of mammals (14), but rather with Proteus spp.

From a practical point of view, and in keeping with the findings of others (15-17), we would like to state that GDH should be considered to be the most important marking enzyme for malarial parasites, including Plasmodium falciparum.

The characteristics mentioned earlier with reference to the enzyme allow us to suggest its possible use in the implementation of a methodology for Plasmodium falciparum malaria diagnosis. Its double characteristic of being a highly immunogenic product of excretion and an enzyme has the potential to be developed into a useful format for a diagnostic test for malaria. Similarly, others (18) have proposed the measurement of Plasmodium falciparum lactate dehydrogenase (pLDH) activity. In our case, GDH(NADP $\left.{ }^{+}\right)$ and proteases currently being studied in our laboratory would allow GDH to be used in both an immunological and an enzyme-type method, a methodology which is already being used with different enzymes (alkaline phosphatase) in other parasites (19). In conclusion, it appears that this technique permits the chromatographic detection of a Plasmodium falciparum excretion antigen that may be used for the production of monoclonal antibodies to improve immunodiagnostic assays for the detection of antigenemia, and opens possibilities as a nonmicroscopic screening method. Furthermore, the GDH isoenzymes of different Plasmodium species (falciparum, vivax, berghei and cathemerium) have shown to be immunologically different (20).

\section{Acknowledgments}

We thank Dr. Stephen Tillet for helpful comments and for reviewing the English text. 


\section{References}

1. Klayman DL (1989). Weeding out malaria. Natural History, 10: 18-91.

2. Saxena N, Pandey VC, Dutta GP \& Ghatak $S$ (1986). Characterisation of lactate dehydrogenase of Plasmodium knowlesi. Molecular Biochemistry and Parasitology, 21: 199-202.

3. Schmidt E (1974). Glutamate dehydrogenase U-V assay. In: Bergmeyer HU (Editor), Methods of Enzymatic Analysis. Academic Press, New York

4. Shermann IW, Peterson I, Tanigoshi L \& Ting IP (1971). The glutamate dehydrogenase of Plasmodium lophurae (avian malaria). Experimental Parasitology, 29: 433-439.

5. Roth J r EF, Schulman S, Vanderberg J \& Olson J (1986). Pathways for the reduction of oxidised glutathione in the Plasmodium falciparum infected erythrocyte: can parasite enzymes replace host red cell glucose-6-phosphate dehydrogenase? Blood, 67: 827-830.

6. Bernard F, Mayer R, Picard I, Deguercy A, Monsigni M \& Schrevel B (1987). Plasmodium berghei and Plasmodium chabaudi: A neutral endopeptidase in parasite extracts and plasma of infected animals. Experimental Parasitology, 64: 90-103.

7. Aikawa M, Miller LH, J ohnson J \& Rabbage J (1988). Erythrocyte entry by malarial parasites: A moving junction between erythrocyte and parasite. J ournal of Cell Biology, 77: 72-82.

8. Trager W \& J ensen J B (1976). Cultivation of malarial parasites. Nature, 237: 621622.

9. Hudson L \& Hay FC (1980). Practical Immunology. Blackwell Scientific Publications, Oxford, England.

10. Laemmli UK (1970). Cleavage of structural proteins during assembly of the head of bacteriophage T4. Nature, 227: 680685.

11. Towbin H, Staehelin T \& Gordon J (1979). Electrophoretic transfer of proteins for polyacrylamide gels to nitrocellulose sheets. Procedure and some applications. Proceedings of the National Academy of Sciences, USA, 76: 4350-4354.

12. Riha I, Haskova $V$, Kaslik J, Maierova $M \&$ Stransky J (1979). The use of polyethyleneglycol for immune complex detection in human serum. Molecular Immunology, 16: 489-493.

13. Van Der J agt $D L$, Hunsaker LA, Kibirige $M$ \& Campos NM (1989). NADPH production by the malarial parasite Plasmodium falciparum. Blood, 74: 471-474.

14. Ling IT, Cooksley S, Bates PA, Hempelmann E \& Wilson RJ M (1986). Antibodies to the glutamate dehydrogenase of Plasmodium falciparum. Parasitology, 92: 313-324.

15. Brett M, Chambers GK, Holder AA, Fincham J RS \& Wooton J C (1976). Muta- tional amino acid replacements in Neurospora crassa NADP+-specific glutamate dehydrogenase. J oumal of Molecular Biology, 106: 1-22.

16. Hempelmann E \& Wilson RJM (1982). Immunoprecipitation of malarial enzymes. Protozoology, 29: 637-642.

17. Eldford BC, Hayes J D, Chulay J D \& Wilson RJ M (1985). Stage-specific transport and metabolism of L-glutamine induced by Plasmodium falciparum in human red cells. Molecular Biochemistry and Parasitology, 12: 267-282.

18. Makler MT, Ries JM, Williams JA, Bancroft J E, Piper RC, Gibbins BL \& Hinrichs DJ (1993). Parasite lactate dehydrogenase as an assay for Plasmodium falciparum drug sensitivity. American $\mathrm{J}$ ournal of Tropical Medicine and Hygiene, 48: 739-741.

19. Pujol de Freychet FH (1988). Evaluación de la fosfatasa alcalina y otros antígenos para el diagnóstico inmunológico de la Esquistosomiasis mansoni, mediante el uso de anticuerpos policlonales y monoclonales. Doctoral thesis, Instituto Venezolano de Investigaciones Científicas, Caracas, Venezuela.

20. Domíngez $N \&$ Rodríguez-Acosta $A$ (1996). Glutamate dehydrogenase antigen detection in Plasmodium falciparum infections. Korean J ournal of Parasitology, 34: 239-246. 